\title{
Characterization of the Industrial Residues of Seven Fruits and Prospection of Their Potential Application as Food Supplements
}

\author{
Soraya de Oliveira Sancho, ${ }^{1}$ Ana Raquel Araújo da Silva, ${ }^{1}$ \\ Allan Nilson de Sousa Dantas, ${ }^{2}$ Ticiane Alencar Magalhães, ${ }^{2}$ Gisele Simone Lopes, ${ }^{2}$ \\ Sueli Rodrigues, ${ }^{1}$ José Maria Correia da Costa, ${ }^{1}$ Fabiano André Narciso Fernandes, ${ }^{3}$ \\ and Maria Goretti de Vasconcelos Silva ${ }^{2}$ \\ ${ }^{1}$ Departamento de Ciência e Tecnologia de Alimentos, Universidade Federal do Ceará, 60440-900 Fortaleza, CE, Brazil \\ ${ }^{2}$ Departamento de Química Analítica e Fisico-Química, Universidade Federal do Ceará, 60440-900 Fortaleza, CE, Brazil \\ ${ }^{3}$ Departamento de Engenharia Química, Universidade Federal do Ceará, 60440-900 Fortaleza, CE, Brazil \\ Correspondence should be addressed to Fabiano André Narciso Fernandes; fabiano@ufc.br
}

Received 8 December 2014; Revised 16 March 2015; Accepted 30 March 2015

Academic Editor: Kequan Zhou

Copyright (C) 2015 Soraya de Oliveira Sancho et al. This is an open access article distributed under the Creative Commons Attribution License, which permits unrestricted use, distribution, and reproduction in any medium, provided the original work is properly cited.

\begin{abstract}
Seven residues from tropical fruit (acerola, cashew apple, guava, mango, papaya, pineapple, and sapota) processing were prospected for physicochemical parameters ( $\mathrm{pH}$, total soluble solids, water activity, reducing sugar, acidity, protein, moisture, ash, and lipids), functional compounds (total phenolic content, anthocyanins, ascorbic acid, and free radical scavenging activity-DPPH), fatty acid profile, and mineral content. Prospection of these industrial residues aimed its use as potential sources for food supplementation. Acerola residue was found to be a valuable source of anthocyanins, phenolics, and vitamin C; cashew apple residue could be a source of unsaturated fatty acids; pineapple and papaya residues could be used, respectively, as manganese and phosphorous source.
\end{abstract}

\section{Introduction}

Several industrial byproducts, which were previously considered food wastes, have now been used as food ingredients and are being used in multimixture formulas. Wheat bran has been considered a byproduct with high nutritional value given its high fiber content and it has been used in bread and breakfast cereals [1]. Rice bran is also being used as a food ingredient given its efficacy in the treatment of chronic diseases $[2,3]$.

Byproducts such as fruit wastes (bagasse, peel, and seeds) can also be potential ingredients in food formulations or raw matter for the extraction of bioactive compounds (phenolics, carotenoids, essential oils, and vitamins), minerals, and antimicrobial agents [4-6]. Studies carried out by Gupta et al. [7] on fruit residues have verified the presence of saturated and unsaturated free fatty acids and minerals (mainly $\mathrm{Ca}, \mathrm{K}$, $\mathrm{Mg}, \mathrm{Na}$, and $\mathrm{P}$ ) that can be important in food supplements. The presence of phenolic compounds and antioxidants on fruit residues has been reported by many researchers $[8,9]$.
The residues from fruit juice industries can account for up to $60 \%$ of the fruit mass and it is a concern in the industry to aggregate value to fruit residues $[10,11]$. Fruit and vegetable wastes and byproducts are often discarded at the expense of the manufacturer. Use of these wastes as a source of vitamins, carotenoids, polyphenols, and minerals may be of considerable economic benefit to food processors. In this paper, we have studied the potential of seven tropical fruits residues to be used as food supplement or to be used in extraction processes.

The fruits selected for this study were acerola (Malpighia glabra L.), guava (Psidium guajava L.), papaya (Carica papaya L.), sapota (Achras sapota L.), cashew apple (Anacardium occidentale L.), pineapple (Ananas comosus L.), and mango (Mangifera indica L.). All these fruits are processed by the industry to produce juices, jams, sauces, sweets, and several other products.

Vitamin C, carotenoids, vitamin E, and phenolic compounds are the most widespread antioxidants in the plant kingdom, where vitamin $\mathrm{C}$ and phenolics are the most 
abundant. Vitamin $\mathrm{C}$ is particularly abundant in raw acerola, guava, and cashew apple. Common carotenoids (xanthophylls and carotenes) have been identified in raw cashew apple, guava, and papaya $[12,13]$.

Phenolics represent a large group of metabolites, which consist of one or more aromatic rings with variable degrees of methoxylation, hydroxylation, and glycosylation, giving color, astringency, and bitterness to fruits. It has been shown that acerola and sapota have phytochemicals such as anthocyanins and nonanthocyanin phenolic compounds [14-16] with antioxidant and antimicrobial activity.

The incorporation of fruit industry wastes into the production of high quality special oils from fruit seeds and peel can increase the market of special oils. The search for new waste materials that provide oils of lipid profile that is similar to those from traditionally consumed oils, and which are also alternative sources of phytosterols and phenolic compounds, is important [16]. In this context, some work has been already done in studying the oil profile of grape, melon, passion fruit, pumpkin, soursop, and tomato [17-20].

In this paper, we have focused on studying the physicochemical parameters $(\mathrm{pH}$, total soluble solids, water activity, reducing sugar, acidity, protein, moisture, ash, and lipids), functional compounds (total phenolic content, anthocyanins, ascorbic acid, and free radical scavenging activity-DPPH), fatty acid profile, and mineral content of these seven fruit wastes.

\section{Material and Methods}

2.1. Samples. Fruit residues were obtained from a fruit pulp processing industry located in Fortaleza, Ceará, Brazil. Seeds and peels of acerola (Malpighia glabra L.), guava (Psidium guajava L.), papaya (Carica papaya L.), sapota (Achras sapota L.), cashew apple bagasse (Anacardium occidentale L.), pineapple (Ananas comosus L.), and mango (Mangifera indica L.) were used in this study. The residues were cut into small pieces, spread on perforated trays, and dried in a hot-air oven at $60^{\circ} \mathrm{C}$ until complete drying $(24 \mathrm{~h})$. The dried samples were grinded to a fine powder $(<180 \mu \mathrm{m})$ [21].

2.2. Ethanolic Extracts Preparation. Ethanolic extracts of the fruit residues were produced using $20 \mathrm{~g}$ of fruit residues and $150 \mathrm{~mL}$ of ethanol. The mixture extraction was carried out in a Soxhlet apparatus operating at $60^{\circ} \mathrm{C}$ for 6 hours. After the extraction process, the mixture was filtered through number 1 Whatman filter paper. The solvent was evaporated under reduce pressure $(100 \mathrm{mmHg})$ using a rotary evaporator (Buchi model R-114) operating at $50^{\circ} \mathrm{C}$.

2.3. Physical-Chemical Characterization of the Residues. Soluble solids were measured at $20^{\circ} \mathrm{C}$ using a digital refractometer (Atago) and expressed as ${ }^{\circ}$ Brix. Titratable acidity was measured according to the AOAC (1995) and the $\mathrm{pH}$ values were determined by direct reading in potentiometer (WTW model 330i/SET). Ash content was determined by mineralization of the samples at $450^{\circ} \mathrm{C}$ (AOAC, 1995). Moisture content and lipid content were determined following the analytical procedure described by AOAC (1995). The total reducing sugars were quantified by the DNS $(3,5-$ dinitrosalicylic) acid method, according to Miller [22]. Water activity was determined using a digital hygrometer Aqualab Model 3TE (Decagon Devices, USA) and protein content was determined according to methodology described by Bradford [23]. References values for the edible portion of the fruit were compared to the data present in the nutrient database of the United States Department of Agriculture [24].

2.4. Determination of Fatty Acids Profile. The extracted lipids were subjected methylation according to the methodology described by Hartman and Lago [25]. The methyl ester content was assayed by gas chromatography in a Thermo Ultra chromatograph provided with a flame ionization detector (FID), using a silica capillary column of $30 \mathrm{~m}$ length and $0.25 \mathrm{~mm}$ inner diameter, packed with polyethylene glycol $(0.25 \mu \mathrm{m}$ film thickness). Solution of methyl esters $(1 \mu \mathrm{L})$ in hexane containing approximately $1 \%$ esters was injected under the following conditions: the carrier gas was helium at a flow rate of $2 \mathrm{~mL} / \mathrm{min}$. The injector and detector temperatures were $250^{\circ} \mathrm{C}$. Oven temperature started at $50^{\circ} \mathrm{C}$ for $1 \mathrm{~min}$, increased at $250^{\circ} \mathrm{C}$ at a rate of $5^{\circ} \mathrm{C} / \mathrm{min}$, and held for $10 \mathrm{~min}$. The identification of compounds was done by comparing the retention time of methyl ester standards.

2.5. Total Phenolic Content (TPC). The fruit-based residue was mixed with 50\% methanol, homogenized, and centrifuged (10,000 rpm for $30 \mathrm{~min})$. The filtrate and the supernatant were collected. Acetone was added 70\% (leaving it to stand for 1 hour), and the samples were centrifuged under the same conditions. The supernatant was filtered and used for quantification of total phenolic compounds according to the spectrophotometric method of Folin-Ciocateau described by Singleton et al. [26], using gallic acid (Vetec, CA) as standard. The absorbance was measured in a spectrophotometer (Spectrum, UV model SP-2000) at $700 \mathrm{~nm}$ and the results were expressed in mg of gallic acid equivalents (mg GAE/100 g).

2.6. Total Anthocyanins. A sample of fruit residue (1 g) was mixed with $50 \mathrm{~mL}$ of an ethanol- $\mathrm{HCl}$ solution $(70 \mathrm{~mL}$ ethanol $70 \%$ and $30 \mathrm{~mL} \mathrm{HCl} 0.1 \%$ ). The mixture was poured into an amber volumetric balloon and kept under refrigeration for 12 hours. After this period the absorbance of the solution was read in a spectrophotometer (Spectrum, model SP-2000 UV), adjusted at $535 \mathrm{~nm}$. The ethanol- $\mathrm{HCl}$ solution was used as blank. Total anthocyanin content was expressed in $\mathrm{mg} / 100 \mathrm{~g}$ of sample [27].

2.7. Ascorbic Acid. A sample of fruit residue $(0.5 \mathrm{~g})$ was added to an Erlenmeyer with $50 \mathrm{~mL}$ of oxalic acid (0.5\%). Titration with standardized 2,6-dichlorophenolindophenol sodium was carried out until persistent pink color occurred, according to the method described by Cox and Pearson [28].

2.8. Scavenging Activity against 1,1-Diphenyl-2-picrylhydrazyl $(D P P H)$. The diluted sample extract $(0.1 \mathrm{~mL})$ was mixed with $3.9 \mathrm{~mL}$ of methanolic solution containing $\mathrm{DPPH}$ radicals 
TABLE 1: Physicochemical properties of tropical fruit residues.

\begin{tabular}{|c|c|c|c|c|c|c|c|}
\hline & Acerola & Cashew apple & Guava & Mango & Papaya & Pineapple & Sapota \\
\hline Water activity & $0.38 \pm 0.01$ & $0.42 \pm 0.02$ & $0.13 \pm 0.01$ & $0.27 \pm 0.01$ & $0.28 \pm 0.01$ & $0.33 \pm 0.01$ & $0.20 \pm 0.01$ \\
\hline $\mathrm{pH}$ & $3.45 \pm 0.03$ & $4.26 \pm 0.02$ & $5.21 \pm 0.01$ & $4.15 \pm 0.01$ & $4.37 \pm 0.01$ & $4.01 \pm 0.02$ & $5.42 \pm 0.01$ \\
\hline Total soluble solids ( ${ }^{\circ}$ Brix) & $3.00 \pm 0.04$ & $3.80 \pm 0.10$ & $1.00 \pm 0.02$ & $5.80 \pm 0.02$ & $6.80 \pm 0.02$ & $6.00 \pm 0.03$ & $2.00 \pm 0.03$ \\
\hline Acidity $(g / 100 \mathrm{~g})$ & $3.60 \pm 0.40$ & $0.97 \pm 0.12$ & $0.53 \pm 0.03$ & $2.17 \pm 0.12$ & $4.15 \pm 0.10$ & $2.57 \pm 0.03$ & $0.75 \pm 0.05$ \\
\hline Proteins (g/100 g) & 0.00 & 0.00 & 0.00 & 0.00 & $9.25 \pm 0.15$ & 0.00 & $6.57 \pm 0.14$ \\
\hline Reducing sugar $(\mathrm{g} / \mathrm{L})$ & $15.29 \pm 0.10$ & $36.00 \pm 0.01$ & $3.68 \pm 0.03$ & $36.39 \pm 0.02$ & $44.81 \pm 0.09$ & $29.67 \pm 0.03$ & $13.67 \pm 0.01$ \\
\hline Moisture (g/100 g) & $4.90 \pm 0.35$ & $5.14 \pm 0.48$ & $3.96 \pm 0.10$ & $3.35 \pm 0.13$ & $7.13 \pm 0.46$ & $6.66 \pm 0.25$ & $4.67 \pm 0.18$ \\
\hline Ash (g/100 g) & $2.07 \pm 0.07$ & $1.41 \pm 0.07$ & $1.20 \pm 0.01$ & $2.66 \pm 0.05$ & $7.58 \pm 0.07$ & $4.96 \pm 0.20$ & $2.14 \pm 0.06$ \\
\hline Lipids $(\mathrm{g} / 100 \mathrm{~g})$ & $2.92 \pm 0.03$ & $2.49 \pm 0.01$ & $11.58 \pm 0.01$ & $1.59 \pm 0.01$ & $4.50 \pm 0.01$ & $0.52 \pm 0.01$ & $11.71 \pm 0.01$ \\
\hline \multicolumn{8}{|c|}{ Values for the edible portion of the fruit (without residues) _ USDA Data (2013) [24] } \\
\hline Total soluble solids ( ${ }^{\circ}$ Brix) & $9.20 \pm 0.18$ & $12.60 \pm 0.25$ & $8.40 \pm 0.17$ & $17.90 \pm 0.35$ & $12.20 \pm 0.25$ & $10.50 \pm 0.20$ & $20.68 \pm 0.50$ \\
\hline Acidity (g/100 g) & $34.40 \pm 0.70$ & $0.16 \pm 0.01$ & $0.44 \pm 0.01$ & $0.14 \pm 0.01$ & $0.15 \pm 0.01$ & $53.50 \pm 1.60$ & $0.16 \pm 0.01$ \\
\hline Proteins (g/100 g) & $0.40 \pm 0.01$ & $0.70 \pm 0.02$ & $2.55 \pm 0.04$ & $0.82 \pm 0.02$ & $0.47 \pm 0.01$ & $0.54 \pm 0.01$ & $0.44 \pm 0.01$ \\
\hline Reducing sugar (g/100 g) & 7.69 & - & 14.32 & 14.98 & 10.82 & 13.12 & 32.10 \\
\hline Reducing sugar (g/L) & 102.5 & - & 190.9 & 199.7 & 144.3 & 174.9 & 428.0 \\
\hline Ash $(g / 100 g)$ & $0.20 \pm 0.01$ & $0.32 \pm 0.01$ & $1.39 \pm 0.01$ & $0.36 \pm 0.01$ & $0.39 \pm 0.01$ & $0.22 \pm 0.01$ & $0.50 \pm 0.01$ \\
\hline Lipids (g/100 g) & $0.30 \pm 0.01$ & 0.00 & $0.95 \pm 0.01$ & $0.38 \pm 0.01$ & $0.26 \pm 0.01$ & $0.12 \pm 0.01$ & $1.10 \pm 0.02$ \\
\hline
\end{tabular}

$\left(6.5 \times 10^{-5} \mathrm{~mol} / \mathrm{L}\right)$. The reduction of the $\mathrm{DPPH}$ radical was measured by monitoring continuously the decrease of absorption at $515 \mathrm{~nm}$. The scavenging percentage of DPPH radical was calculated according to the following formula:

$$
\text { \%scavenging effect }=100 \times\left[\frac{(\mathrm{ADPPH}-\mathrm{As})}{\mathrm{ADPPH}}\right] \text {, }
$$

where ADPPH is the absorbance of the DPPH solution and As is the absorbance of the mixture containing the methanolic extract and DPPH solution.

2.9. Mineral Content. All measurements were carried out using a simultaneous inductively coupled plasma optical emission spectrometer (ICP-OES) with axial and radial views (Optima 4300 Series, Perkin Elmer, USA).

Acid digestions were prepared by using a microwave oven equipped with a rotor for six quartz vessels (Multiwave, Anton Paar, Graz, Austria). Samples of $0.2 \mathrm{~g}$ were weighed, mixed with $2.0 \mathrm{~mL}$ of $\mathrm{H}_{2} \mathrm{O}_{2}$ and $3.0 \mathrm{~mL}$ of $\mathrm{HNO}_{3}$, and transferred to quartz vessels. The digestion heating program consisted of the following three steps: $5 \mathrm{~min}$ at $100-500 \mathrm{~W}$ of power; $15 \mathrm{~min}$ at $800 \mathrm{~W}$ of power; cooling at maximum air flow rate for $15 \mathrm{~min}$ to cool down the vessels to room temperature. After cooling, $20 \mathrm{~mL}$ of ultrapure water was added to dilute the content of the vessels. Blanks were treated the same way but without adding the fruit residue samples. Three replicated measurements were performed for these experiments. Minerals content was calculated based on calibration curves made from standard solutions of the minerals (Acros Organics, Geel, Belgium).

\section{Results and Discussion}

The mean and standard deviations of the physical-chemical parameters found for fruit residues are presented in Table 1.
The table also presents reference values for the physicalchemical parameters for the edible portion of the fruit. Fruit residues have low content of crude protein, lipid, and ash, being the main compounds of the reducing sugars. Exceptions were sapota residue that presented high lipid and protein content and papaya residue that presented high protein content.

All residues presented water activity lower than 0.42 . Thus, the residues are not conducive to microbial growth, since water activities below 0.6 will not allow the growth of microorganisms or the production of toxins [29]. As such, the residue could be stored as it is for further processing without compromising it.

In this study, the $\mathrm{pH}$ ranged from 3.45 (acerola residue) to 5.42 (sapodilla residue). Generally, only food with $\mathrm{pH}$ equal to or lower than 4.6 is considered acidic food because it limits the growth of the extremely dangerous microorganism Clostridium botulinum [30]. Under this point of view, the residues of acerola, papaya, cashew apple, pineapple, and mango could be considered acidic. The residues of guava and sapota would have to be artificially acidified to lower their $\mathrm{pH}$ to levels below or equal to 4.6. The results obtained herein were similar to the results found by Mercali et al. [31] for acerola pulp.

For the acidity parameter, measured in $\mathrm{g} / 100 \mathrm{~g}$ of citric acid, it was observed that all samples of fruit residues showed significant differences between them, ranging from $0.53 \mathrm{~g} / 100 \mathrm{~g}$ (guava residue) to $4.15 \mathrm{~g} / 100 \mathrm{~g}$ (papaya residue). Cvetković et al. [32] in their study with dried fruits, typical of Serbia, found levels of total acidity of $0.8,1.30,1.34$, and $1.90 \mathrm{~g} / 100 \mathrm{~g}$ for apricot, cranberry, wild apple, and rose hip, respectively.

Usually, fruits are rich in sugars (glucose and fructose), whose determination is important to evaluate the potential of these residues as raw matter also for fermentation. 
TABLE 2: Fatty acids composition in seven fruit residues.

\begin{tabular}{|c|c|c|c|c|c|c|c|}
\hline & Acerola & Cashew apple & Guava & Mango & Papaya & Pineapple & Sapota \\
\hline C14:0 myristic acid & 1.1 & 0.4 & - & - & 0.6 & - & - \\
\hline C16:0 palmitic acid & 27.7 & 34.0 & 57.9 & 75.6 & 33.0 & 48.2 & 59.0 \\
\hline C16:1 palmitoleic acid & 1.4 & 0.5 & - & 2.9 & 0.6 & 一 & - \\
\hline $\mathrm{C} 18: 0$ stearic acid & 14.2 & 一 & - & - & 2.7 & - & 13.5 \\
\hline C18:1 oleic acid & 23.2 & 65.0 & 23.8 & 21.5 & 62.5 & 51.8 & 27.5 \\
\hline C18:2 linoleic acid & 32.2 & - & - & - & 0.6 & - & - \\
\hline C20:0 arachidic acid & - & - & 18.3 & - & - & - & - \\
\hline
\end{tabular}

The results showed that lowest concentration observed was found for guava residue and the highest value for papaya residue $(3.68 \mathrm{~g} / \mathrm{L}$ and $44.81 \mathrm{~g} / \mathrm{L}$, resp.). Given the amount of sugars, cashew apple, papaya, mango, and pineapple residues would be suitable for fermentation purposes. On the other hand, guava residue would be suitable as low sugar food supplement. Cvetković et al. [32] also found a wide variation of this parameter in their study, finding values of 9.72, 16.50, 23.23, and $61.21 \%$ for the following dried fruits: rose hip, wild apple, apricot, and cranberry, respectively. In comparison to the edible portion of the fruit, the residues have presented a lower amount of sugars (between 10 to $50 \%$ of the total sugar of the edible portion of the fruit).

Only the samples of sapota and papaya residues showed high content of protein, probably due to high percentage of seeds and their composition. The types of colloidal macromolecules found in seeds often are hydrophilic and have a large number of ionic groups, such as proteins. However, in this study, protein was not detected in the other residues with seeds, for example, acerola. The edible portion of the fruits did not present high amounts of protein and, in comparison, most residues have presented even lower amount of proteins, except for papaya and sapota. The results show that most of the proteins from papaya and sapota are placed in the residue portion.

An important parameter in a fruit or vegetable powder extract is its lipid content [33]. Guava and sapota residues have presented high amounts of lipid content, which were higher than that reported for banana fibers $(5.8 \mathrm{~g} / 100 \mathrm{~g}$ dry sample) or grapefruit dietary fiber $(3.2 \mathrm{~g} / 100 \mathrm{~g}$ dry sample) $[34,35]$. The results show that the amount of lipids in the residues is much higher (up to 10x higher) than the amount in the edible portion of the fruit. As such, the residues are a good source of lipids in comparison to the edible portion of the fruit.

Table 2 presents the fatty acids composition of the seven fruit residues. The fatty acids profile of the residues showed mainly the presence of palmitic and oleic acids, which are common in fruits seeds and peels. Only acerola presented high concentration of linoleic acid.

According to Morales-de la Peña et al. [36], the consumption of monounsaturated fatty acids (MUFA), especially oleic acid ( $\omega-9)$, has been shown to decrease plasma triacylglycerol and cholesterol concentrations in healthy normolipidemic subjects. In this aspect the use of cashew apple, papaya, and pineapple extracts may be indicated. Polyunsaturated fatty acids (PUFA), such as linoleic ( $\omega-6)$ and linolenic acids ( $\omega-3)$, contribute to the prevention of atherosclerosis, cancer, heart diseases, and diabetes [37]. Under this viewpoint, the use of acerola extracts may be indicated.

Products such as milk, whose fat contains more than $70 \%$ of saturated fatty acids, can be supplemented with unsaturated fatty acids to enhance its nutritional value [38].

The use of fruit residues in food products or supplements is largely determined by their functionality, which depends on physicochemical properties and by food processing; however, their impact on sensory characteristics of food must be considered [39]. The results of the determinations of functional properties in the extracts of fruits residues are presented in Table 3.

There was significant difference in the total phenolic content (TPC), anthocyanins, and ascorbic acid among the extracts studied herein. Acerola residue showed the highest TPC, anthocyanins and ascorbic acid, which was expected given the high amounts of phenolics, anthocyanins, and ascorbic acid in the fruit. This result shows that fruit residues retain high concentrations of these compounds. In comparison to the edible portion of the fruit, the residues have presented a lower amount of total phenolics. However, it is important to mention that the total phenolic content in the residues is still high, especially for acerola, mango, and papaya residues. The total phenolic content in acerola residues is higher than the amount of phenolics present in the edible portion of all the other fruits studied herein. Thus, acerola residue can be considered an important source of phenolics and should be used in food supplements.

Appreciable amounts of anthocyanin were found in acerola extract $(60.83 \mathrm{mg} / 100 \mathrm{~g})$, which also has contributed to the high antioxidant property of this residue. High concentrations of antioxidants have been reported previously by several authors in residues of grape, passion fruit, banana, tangerine, and lychee $[5,8,9,19,40]$, but acerola residue showed higher antioxidant capacity.

Anthocyanins were found in higher amounts in the residues of acerola, guava, papaya, pineapple, and sapota than in the edible portion of the fruit. The results show that most of the anthocyanins are found in the peels of the fruit and processing them to extract these anthocyanins can be of commercial interest.

Many fruits are regarded as good source of ascorbic acid, commonly known as vitamin C. The content of this vitamin in the extracts was generally high for all fruit residues; however, 
TABLE 3: Functional properties in fruits residues and in the edible portion of the fruit.

\begin{tabular}{|c|c|c|c|c|}
\hline Fruit & TPC (mg GAE/100 g) & Anthocyanins (mg/100 g) & Ascorbic acid (mg/100 g) & Antioxidant activity (\%) \\
\hline Acerola & $173.30 \pm 0.05$ & $60.83 \pm 0.17$ & $170.73 \pm 0.46$ & $48.21 \pm 0.06$ \\
\hline Cashew apple & $13.20 \pm 0.04$ & $2.46 \pm 0.01$ & $30.49 \pm 0.06$ & $17.80 \pm 0.05$ \\
\hline Guava & $2.80 \pm 0.01$ & $1.55 \pm 0.01$ & $39.63 \pm 0.03$ & $15.97 \pm 0.01$ \\
\hline Mango & $42.30 \pm 0.03$ & $7.47 \pm 0.02$ & $36.58 \pm 0.04$ & $44.49 \pm 0.02$ \\
\hline Papaya & $34.65 \pm 0.01$ & $11.56 \pm 0.01$ & $121.95 \pm 0.06$ & $25.03 \pm 0.01$ \\
\hline Pineapple & $15.18 \pm 0.04$ & $10.91 \pm 0.02$ & $51.83 \pm 0.03$ & $33.47 \pm 0.01$ \\
\hline Sapota & $4.35 \pm 0.03$ & $4.09 \pm 0.02$ & $36.58 \pm 0.02$ & $28.56 \pm 0.04$ \\
\hline \multicolumn{5}{|c|}{ Values for the edible portion of the fruit (without residues) _-USDA Data (2013) [24] } \\
\hline Acerola & $658.00 \pm 12.00$ & $8.40 \pm 0.16$ & $506.00 \pm 11.00$ & $70.00 \pm 1.40$ \\
\hline Cashew apple & $95.00 \pm 1.80$ & $21.16 \pm 0.42$ & $167.00 \pm 3.20$ & $93.00 \pm 1.86$ \\
\hline Guava & $159.80 \pm 3.10$ & $0.24 \pm 0.01$ & $71.40 \pm 1.41$ & $49.10 \pm 1.01$ \\
\hline Mango & $59.80 \pm 1.10$ & $23.00 \pm 0.41$ & $16.20 \pm 3.20$ & $23.10 \pm 0.46$ \\
\hline Papaya & $53.20 \pm 1.05$ & $0.69 \pm 0.02$ & $8.60 \pm 0.17$ & $54.00 \pm 1.20$ \\
\hline Pineapple & $38.10 \pm 0.70$ & $0.32 \pm 0.01$ & $13.00 \pm 0.26$ & $16.59 \pm 0.32$ \\
\hline Sapota & $13.50 \pm 0.26$ & $0.46 \pm 0.01$ & $3.90 \pm 0.07$ & $3.51 \pm 0.07$ \\
\hline \multicolumn{2}{|c|}{ Ascorbic acid (reference) } & & & $89.57 \pm 0.05$ \\
\hline
\end{tabular}

TABLE 4: Pearson correlation between the value of TPC, total anthocyanins, and vitamin $\mathrm{C}$ and antioxidant activity.

\begin{tabular}{lc}
\hline Variable & Correlations $(r$ value $)$ \\
\hline TPC $(\mathrm{mg}$ GAE$/ 100 \mathrm{~g})$ & 0.73 \\
Total anthocyanins $(\mathrm{mg} / 100 \mathrm{~g})$ & 0.70 \\
Ascorbic acid $(\mathrm{mg} / 100 \mathrm{~g})$ & 0.49 \\
\hline
\end{tabular}

the highest amounts were found in acerola residue. The amount of vitamin $\mathrm{C}$ found in some residues was higher than that in the edible portion of the fruit thus showing the nutritional value of the peels that could be used in the production of vitamin $\mathrm{C}$. The vitamin $\mathrm{C}$ content in acerola residues was higher than the amount present in the edible portion of all the other fruits studied herein. Thus, acerola residue can be also considered an important source of vitamin $\mathrm{C}$ and should be used in food supplements.

The results obtained herein for TPC and antioxidant activity were higher than the values found for wheat flour residue, which is commonly used in food supplements [41, 42].

Table 4 shows the correlation between the total phenolic content (TPC), total anthocyanins, and ascorbic acid in relation to the antioxidant activity in the samples. A Pearson's correlation close to 1 indicates a positive relationship between $X$ and $Y$. A correlation close to -1 indicates a negative relationship. A correlation close to 0 indicates the absence of relationship between the two variables. Values between 0.90 and 1 were considered a very strong positive correlation and between 0.6 and 0.9 were considered strong [43]. The levels of total phenolic compounds (TPC) had significant and strong correlation $(r=0.73, P<0.05)$ for the antioxidant activity and total anthocyanins $(r=0.70, P<0.05)$. Gardner et al. [44] also found strong correlation for phenolic compounds $(r=0.97)$ in non-citrus fruit juices. Given the correlation values, the TPC of the fruit residues could be considered the main contributors to the antioxidant activity of these products.

The mineral composition in the fruit residues is presented in Table 5. Results have shown that the most abundant mineral in the fruit residues was potassium, followed by phosphorus, calcium, and magnesium. Given the very low concentrations, almost none of the fruit residues could be used to supplement manganese, zinc, and iron. The amount of minerals present in the residues was, in general, much higher than the amount found in the edible portion of the fruit. The only exceptions were the amount of iron in cashew apple and the amount of sodium in sapota. This result shows the potential of these fruit residues as mineral supplements.

Table 6 presents the recommended daily intake of minerals and the contribution of a portion of $10 \mathrm{~g}$ of each fruit residue to the recommended daily intake for man and woman. Pineapple residue may be a remarkable source of manganese since only $10 \mathrm{~g}$ of the dried residue can contribute to more than $100 \%$ of the RDI for man and $92 \%$ of the RDI for woman.

Mango and cashew apple residues can also be considered good sources of manganese, since they could contribute to more than $10 \%$ of the RDI of manganese (for a portion of $10 \mathrm{~g}$ of dried residue used as food supplement). Papaya could be used as a source for phosphorus, since a portion of $10 \mathrm{~g}$ of dried residue would also contribute to more than $10 \%$ of the RDI.

All residues have presented very low amounts of sodium. This was an important result because sodium contributes greatly to hypertension and aggravates other heart conditions [45].

\section{Conclusions}

Some fruit residues, such as acerola, pineapple, cashew apple, mango, and papaya residues, could be used as food 
TABLE 5: Mineral content in fruit residues $(\mathrm{mg} / \mathrm{g})$.

\begin{tabular}{|c|c|c|c|c|c|c|c|c|}
\hline & $\mathrm{Ca}$ & $\mathrm{Fe}$ & $\mathrm{K}$ & $\mathrm{Mg}$ & $\mathrm{Mn}$ & $\mathrm{Na}$ & $\mathrm{P}$ & $\mathrm{Zn}$ \\
\hline Acerola & $2.58 \pm 0.06$ & $0.05 \pm 0.00$ & $6.79 \pm 0.40$ & $1.02 \pm 0.04$ & $0.00 \pm 0.00$ & $0.26 \pm 0.02$ & $1.86 \pm 0.11$ & $0.01 \pm 0.00$ \\
\hline Cashew apple & $0.34 \pm 0.02$ & $0.02 \pm 0.00$ & $4.92 \pm 0.24$ & $1.03 \pm 0.04$ & $0.02 \pm 0.00$ & $0.25 \pm 0.00$ & $1.28 \pm 0.02$ & $0.01 \pm 0.00$ \\
\hline Guava & $0.49 \pm 0.01$ & $0.04 \pm 0.01$ & $3.37 \pm 0.09$ & $0.95 \pm 0.02$ & $0.01 \pm 0.00$ & $0.09 \pm 0.00$ & $2.61 \pm 0.01$ & $0.02 \pm 0.00$ \\
\hline Mango & $2.77 \pm 0.26$ & $0.02 \pm 0.00$ & $11.20 \pm 1.05$ & $1.16 \pm 0.09$ & $0.03 \pm 0.00$ & $0.26 \pm 0.07$ & $0.92 \pm 0.01$ & $0.00 \pm 0.00$ \\
\hline Papaya & $2.84 \pm 0.11$ & $0.03 \pm 0.00$ & $43.00 \pm 1.27$ & $2.38 \pm 0.11$ & $0.01 \pm 0.00$ & $0.98 \pm 0.02$ & $8.07 \pm 0.40$ & $0.02 \pm 0.00$ \\
\hline Pineapple & $3.40 \pm 0.02$ & $0.03 \pm 0.00$ & $25.46 \pm 0.46$ & $1.34 \pm 0.02$ & $0.21 \pm 0.00$ & $0.48 \pm 0.01$ & $1.28 \pm 0.06$ & $0.01 \pm 0.00$ \\
\hline Sapota & $3.63 \pm 0.17$ & $0.03 \pm 0.00$ & $5.04 \pm 0.17$ & $0.91 \pm 0.03$ & $0.01 \pm 0.00$ & $0.83 \pm 0.03$ & $1.06 \pm 0.06$ & $0.01 \pm 0.00$ \\
\hline \multicolumn{9}{|c|}{ Values for the edible portion of the fruit (without residues) } \\
\hline Acerola & $0.12 \pm 0.01$ & $0.00 \pm 0.00$ & $1.46 \pm 0.15$ & $0.02 \pm 0.00$ & $0.00 \pm 0.00$ & $0.07 \pm 0.01$ & $0.11 \pm 0.01$ & $0.00 \pm 0.00$ \\
\hline Cashew apple & $0.08 \pm 0.01$ & $0.13 \pm 0.01$ & $3.34 \pm 0.33$ & $0.03 \pm 0.00$ & $0.00 \pm 0.00$ & $0.20 \pm 0.02$ & $0.44 \pm 0.04$ & $0.02 \pm 0.00$ \\
\hline Guava & $0.18 \pm 0.02$ & $0.00 \pm 0.00$ & $4.17 \pm 0.42$ & $0.02 \pm 0.00$ & $0.00 \pm 0.00$ & $0.02 \pm 0.00$ & $0.40 \pm 0.04$ & $0.00 \pm 0.00$ \\
\hline Mango & $0.11 \pm 0.01$ & $0.00 \pm 0.00$ & $1.68 \pm 0.17$ & $0.01 \pm 0.00$ & $0.00 \pm 0.00$ & $0.01 \pm 0.00$ & $0.14 \pm 0.01$ & $0.00 \pm 0.00$ \\
\hline Papaya & $0.20 \pm 0.02$ & $0.00 \pm 0.00$ & $1.82 \pm 0.18$ & $0.02 \pm 0.00$ & $0.00 \pm 0.00$ & $0.08 \pm 0.01$ & $0.10 \pm 0.01$ & $0.00 \pm 0.00$ \\
\hline Pineapple & $0.13 \pm 0.01$ & $0.00 \pm 0.00$ & $1.09 \pm 0.11$ & $0.01 \pm 0.00$ & $0.01 \pm 0.00$ & $0.01 \pm 0.00$ & $0.08 \pm 0.01$ & $0.00 \pm 0.00$ \\
\hline Sapota & $0.21 \pm 0.02$ & $0.01 \pm 0.00$ & $1.93 \pm 0.20$ & $0.01 \pm 0.00$ & $0.00 \pm 0.00$ & $1.20 \pm 0.12$ & $0.12 \pm 0.01$ & $0.00 \pm 0.00$ \\
\hline
\end{tabular}

TABLE 6: Recommended daily intake (RDI) of minerals: the contribution (\%) of a portion of $10 \mathrm{~g}$ of each fruit residue to the recommended daily intake for man and woman.

\begin{tabular}{lcccccccc}
\hline & $\mathrm{Ca}$ & $\mathrm{Fe}$ & $\mathrm{K}$ & $\mathrm{Mg}$ & $\mathrm{Mn}$ & $\mathrm{Na}$ & $\mathrm{P}$ & $\mathrm{Zn}$ \\
\hline RDI (man/woman) & $1000 / 1300$ & $8 / 18$ & 4700 & $320 / 420$ & $1.8 / 2.3$ & 2300 & 700 & $8 / 11$ \\
Acerola & $2.6 / 2.0$ & $6.2 / 2.7$ & 1.4 & $3.2 / 2.4$ & $3.1 / 2.4$ & 0.1 & 2.6 & $1.1 / 0.8$ \\
Cashew apple & $0.3 / 0.3$ & $3.0 / 1.3$ & 1.0 & $3.2 / 2.4$ & $12.6 / 10.4$ & 0.1 & 1.8 & $1.7 / 1.2$ \\
Guava & $0.5 / 0.4$ & $5.0 / 2.2$ & 0.7 & $3.0 / 2.3$ & $5.8 / 4.6$ & 0.0 & 3.7 & $2.1 / 1.5$ \\
Mango & $2.8 / 2.1$ & $2.3 / 1.0$ & 2.4 & $3.6 / 2.8$ & $14.6 / 11.4$ & 0.1 & 1.3 & $0.5 / 0.4$ \\
Papaya & $2.8 / 2.2$ & $3.7 / 1.6$ & 9.2 & $7.4 / 5.7$ & $6.7 / 5.3$ & 0.4 & 11.5 & $2.2 / 1.6$ \\
Pineapple & $3.4 / 2.6$ & $4.3 / 1.9$ & 5.4 & $4.2 / 3.2$ & $117.7 / 92.1$ & 0.2 & 1.8 & $0.8 / 0.6$ \\
Sapota & $3.6 / 2.8$ & $3.3 / 1.5$ & 1.1 & $2.8 / 2.2$ & $7.9 / 6.2$ & 0.4 & 1.5 & $0.7 / 0.5$ \\
\hline
\end{tabular}

supplements. These residues are rich in some nutritional compounds that may highly contribute towards the recommended daily intake of the compound. Among all residues, acerola residue showed to present very high concentration of antioxidants, making this residue potential high value subproduct. Acerola residue was found to be a valuable source of anthocyanins, phenolics, and vitamin C; cashew apple residue could be a source of unsaturated fatty acids; pineapple and papaya residues could be used, respectively, as manganese and phosphorous source.

\section{Conflict of Interests}

The authors declare that there is no conflict of interests regarding the publication of this paper.

\section{Acknowledgments}

The authors thank FUNCAP (Ceará State Foundation for Scientific and Technological Development Support) for providing the Ph.D. scholarship, CNPq for the financial support, and the fruit processing company Natupolpa for supplying the residues used in this study.

\section{References}

[1] Y. Hemery, M. Chaurand, U. Holopainen et al., "Potential of dry fractionation of wheat bran for the development of food ingredients, part I: influence of ultra-fine grinding," Journal of Cereal Science, vol. 53, no. 1, pp. 1-8, 2011.

[2] S. M. A. Domene, H. R. Torin, and J. Amaya-Farfán, “Dietary zinc improves and calcium depresses growth and zinc uptake in rats fed rice bran," Nutrition Research, vol. 21, no. 12, pp. 14931500, 2001.

[3] G. L. Faccin, L. A. Miotto, L. N. Vieira, P. L. M. Barreto, and E. R. Amante, "Chemical, sensorial and rheological properties of a new organic rice bran beverage," Rice Science, vol. 16, no. 3, pp. 226-234, 2009.

[4] G. Shui and L. P. Leong, "Residue from star fruit as valuable source for functional food ingredients and antioxidant nutraceuticals," Food Chemistry, vol. 97, no. 2, pp. 277-284, 2006.

[5] A. C. de Oliveira, I. B. Valentim, C. A. Silva et al., "Total phenolic content and free radical scavenging activities of methanolic extract powders of tropical fruit residues," Food Chemistry, vol. 115, no. 2, pp. 469-475, 2009.

[6] M. Aguedo, S. Kohnen, N. Rabetafika et al., "Composition of by-products from cooked fruit processing and potential use in food products," Journal of Food Composition and Analysis, vol. 27, no. 1, pp. 61-69, 2012. 
[7] P. Gupta, A. Sharma, and A. K. Verma, "Evaluation of nutritional constituent and fatty acid profiles of different tropical fruit residues," Current Nutrition and Food Science, vol. 8, no. 2, pp. 80-85, 2012.

[8] J. Sun, Y. Jiang, J. Shi et al., "Antioxidant activities and contents of polyphenol oxidase substrates from pericarp tissues of litchi fruit," Food Chemistry, vol. 119, no. 2, pp. 753-757, 2010.

[9] R. Martínez, P. Torres, M. A. Meneses, J. G. Figueroa, J. A. PérezÁlvarez, and M. Viuda-Martos, "Chemical, technological and in vitro antioxidant properties of mango, guava, pineapple and passion fruit dietary fibre concentrate," Food Chemistry, vol. 135, no. 3, pp. 1520-1526, 2012.

[10] A. A. A. Mohdaly, M. A. Sarhan, I. Smetanska, and A. Mahmoud, "Antioxidant properties of various solvent extracts of potato peel, sugar beet pulp and sesame cake," Journal of the Science of Food and Agriculture, vol. 90, no. 2, pp. 218-226, 2010.

[11] G. Pande and C. C. Akoh, "Organic acids, antioxidant capacity, phenolic content and lipid characterisation of Georgia-grown underutilized fruit crops," Food Chemistry, vol. 120, no. 4, pp. 1067-1075, 2010.

[12] U. G. Chandrika, K. S. S. P. Fernando, and K. K. D. S. Ranaweera, "Carotenoid content and in vitro bioaccessibility of lycopene from guava (Psidium guajava) and watermelon (Citrullus lanatus) by high-performance liquid chromatography diode array detection," International Journal of Food Sciences and Nutrition, vol. 60, no. 7, pp. 558-566, 2009.

[13] D. B. Rodriguez-Amaya, J. Amaya-Farfan, and M. Kimura, "Carotenoid composition of Brazilian fruits and vegetables," Acta Horticulturae, vol. 744, pp. 409-416, 2007.

[14] L. Delva and R. Goodrich-Schneider, "Antioxidant activity and antimicrobial properties of phenolic extracts from acerola (Malpighia emarginata DC) fruit," International Journal of Food Science and Technology, vol. 48, no. 5, pp. 1048-1056, 2013.

[15] V. V. de Rosso, S. Hillebrand, E. Cuevas Montilla, F. O. Bobbio, P. Winterhalter, and A. Z. Mercadante, "Determination of anthocyanins from acerola (Malpighia emarginata DC.) and açai (Euterpe oleracea Mart.) by HPLC-PDA-MS/MS," Journal of Food Composition and Analysis, vol. 21, no. 4, pp. 291-299, 2008.

[16] A. L. A. Vendramini and L. C. Trugo, "Phenolic compounds in acerola fruit (Malpighia punicifolia L.)," Journal of the Brazilian Chemical Society, vol. 15, no. 5, pp. 664-668, 2004.

[17] A. C. Silva and N. Jorge, "Bioactive compouds of the lipid fractions of agro-industrial waste," Food Research International, vol. 66, pp. 493-500, 2014.

[18] L. S. Dias, D. M. M. Luzia, and N. Jorge, "Physicochemical and bioactive properties of Hymenaea courbaril L. pulp and seed lipid fraction," Industrial Crops and Products, vol. 49, pp. 610618, 2013.

[19] T. Maier, A. Schieber, D. R. Kammerer, and R. Carle, "Residues of grape (Vitis vinifera L.) seed oil production as a valuable source of phenolic antioxidants," Food Chemistry, vol. 112, no. 3, pp. 551-559, 2009.

[20] H. Wu, J. Shi, S. Xue et al., "Essential oil extracted from peach (Prunus persica) kernel and its physicochemical and antioxidant properties," LWT_Food Science and Technology, vol. 44, no. 10, pp. 2032-2039, 2011.

[21] Y. S. Velioglu, G. Mazza, L. Gao, and B. D. Oomah, "Antioxidant activity and total phenolics in selected fruits, vegetables, and grain products," Journal of Agricultural and Food Chemistry, vol. 46, no. 10 , pp. 4113-4117, 1998.
[22] G. L. Miller, "Use of dinitrosalicylic acid reagent for determination of reducing sugar," Analytical Chemistry, vol. 31, no. 3, pp. 426-428, 1959.

[23] M. M. Bradford, "A rapid and sensitive method for the quantitation of microgram quantities of protein utilizing the principle of protein dye binding," Analytical Biochemistry, vol. 72, no. 1-2, pp. 248-254, 1976.

[24] USDA, United States Department of Agriculture. Basic Report. Nutrient data for 09139. National Nutrient Database for Standard Reference. Release 25, USDA, Washington, DC, USA, 2013, http://ndb.nal.usda.gov/ndb/search/list.

[25] L. Hartman and R. C. A. Lago, "Rapid preparation of fatty acid methyl esters from lipids," Laboratory Practice, vol. 22, pp. 475476, 1973.

[26] V. L. Singleton, R. Orthofer, and R. M. Lamuela-Raventós, "Analysis of total phenols and other oxidation substrates and antioxidants by means of folin-ciocalteu reagent," Methods in Enzymology, vol. 299, pp. 152-178, 1999.

[27] F. J. Francis, "Analysis of anthocyanins," in Anthocyanins of Food Colours, P. Markakis, Ed., pp. 181-207, Academic Press, New York, NY, USA, 1982.

[28] H. E. Cox and D. Pearson, Tecnicas de laboratorio para el analisis de alimentos, Acribia, Zaragoza, Spain, 1976.

[29] M. C. Zamora and J. Chirife, "Determination of water activity change due to crystallization in honeys from Argentina," Food Control, vol. 17, no. 1, pp. 59-64, 2006.

[30] Z.-H. Hu, G. Wang, and H.-Q. Yu, "Anaerobic degradation of cellulose by rumen microorganisms at various ph values," Biochemical Engineering Journal, vol. 21, no. 1, pp. 59-62, 2004.

[31] G. D. Mercali, J. R. Sarkis, D. P. Jaeschke, I. C. Tessaro, and L. D. F. Marczak, "Physical properties of acerola and blueberry pulps," Journal of Food Engineering, vol. 106, no. 4, pp. 283-289, 2011.

[32] B. R. Cvetković, B. V. Filipčev, M. I. Bodroža-Solarov, Ž. M. Bardić, and M. B. Sakač, "Chemical composition of dried fruits as a value added ingredient in bakery products," Food Processing, Quality and Safety, vol. 36, no. 1-2, pp. 15-19, 2009.

[33] M. Viuda-Martos, Y. Ruiz-Navajas, A. Martin-Sánchez et al., "Chemical, physico-chemical and functional properties of pomegranate (Punica granatum L.) bagasses powder coproduct," Journal of Food Engineering, vol. 110, no. 2, pp. 220224, 2012.

[34] T. H. Emaga, R. H. Andrianaivo, B. Wathelet, J. T. Tchango, and M. Paquot, "Effects of the stage of maturation and varieties on the chemical composition of banana and plantain peels," Food Chemistry, vol. 103, no. 2, pp. 590-600, 2007.

[35] F. Figuerola, M. L. Hurtado, A. M. Estévez, I. Chiffelle, and F. Asenjo, "Fibre concentrates from apple pomace and citrus peel as potential fibre sources for food enrichment," Food Chemistry, vol. 91, no. 3, pp. 395-401, 2005.

[36] M. Morales-de la Peña, L. Salvia-Trujillo, M. A. Rojas-Graü, and O. Martín-Belloso, "Impact of high intensity pulsed electric fields or heat treatments on the fatty acid and mineral profiles of a fruit juice-soymilk beverage during storage," Food Control, vol. 22, no. 12, pp. 1975-1983, 2011.

[37] G. Chahoud, Y. W. Aude, and J. L. Mehta, "Dietary recommendations in the prevention and treatment of coronary heart disease: do we have the ideal diet yet?" The American Journal of Cardiology, vol. 94, no. 10, pp. 1260-1267, 2004.

[38] E. Lopez-Huertas, "Health effects of oleic acid and long chain omega-3 fatty acids (EPA and DHA) enriched milks. A review of intervention studies," Pharmacological Research, vol. 61, no. 3, pp. 200-207, 2010. 
[39] S. M. Tosh and S. Yada, "Dietary fibres in pulse seeds and fractions: characterization, functional attributes, and applications," Food Research International, vol. 43, no. 2, pp. 450-460, 2010.

[40] A. Llobera and J. Cañellas, "Antioxidant activity and dietary fibre of Prensal Blanc white grape (Vitis vinifera) by-products," International Journal of Food Science and Technology, vol. 43, no. 11, pp. 1953-1959, 2008.

[41] B. Verma, P. Hucl, and R. N. Chibbar, "Phenolic acid composition and antioxidant capacity of acid and alkali hydrolysed wheat bran fractions," Food Chemistry, vol. 116, no. 4, pp. 947954, 2009.

[42] K.-H. Kim, R. Tsao, R. Yang, and S. W. Cui, "Phenolic acid profiles and antioxidant activities of wheat bran extracts and the effect of hydrolysis conditions," Food Chemistry, vol. 95, no. 3, pp. 466-473, 2006.

[43] F. J. Gravetter and L. B. Wallnau, Essentials of Statistics for the Behavioral Sciences, Cengage Learning, Wadsworth, Ohio, USA, 7th edition, 2011.

[44] P. T. Gardner, T. A. C. White, D. B. McPhail, and G. G. Duthie, "The relative contributions of vitamin C, carotenoids and phenolics to the antioxidant potential of fruit juices," Food Chemistry, vol. 68, no. 4, pp. 471-474, 2000.

[45] M. P. Do Amaral Zaitune, M. B. De Azevedo Barros, C. L. Galvão César, L. Carandina, and M. Goldbaum, "Arterial hypertension in the elderly: prevalence, associated factors, and control practices in Campinas, São Paulo, Brazil," Cadernos de Saude Publica, vol. 22, no. 2, pp. 285-294, 2006. 

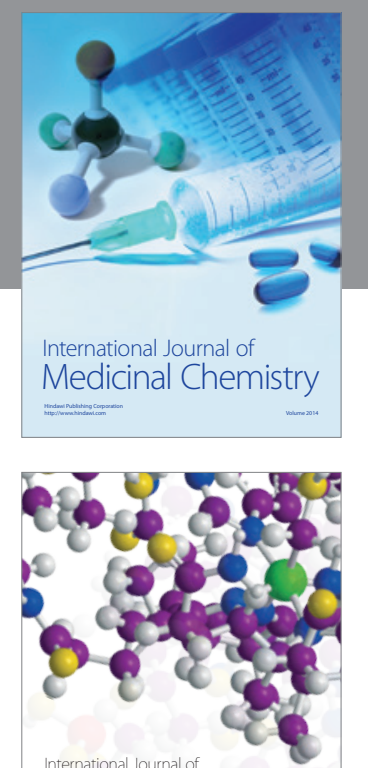

\section{Carbohydrate} Chemistry

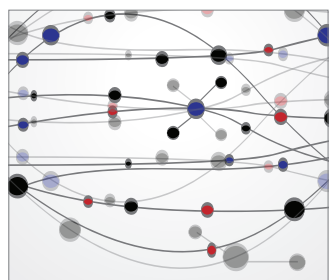

The Scientific World Journal
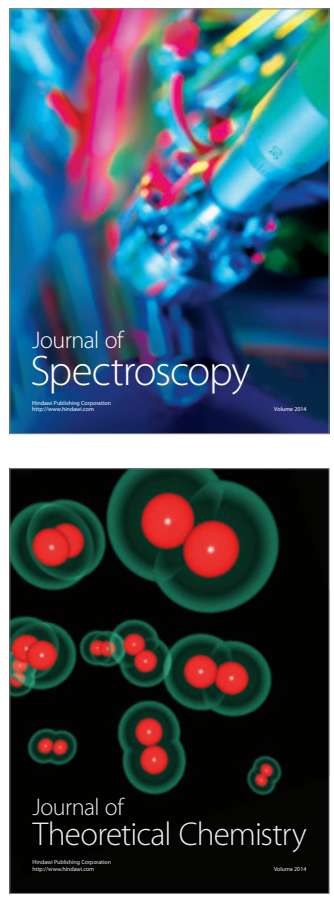
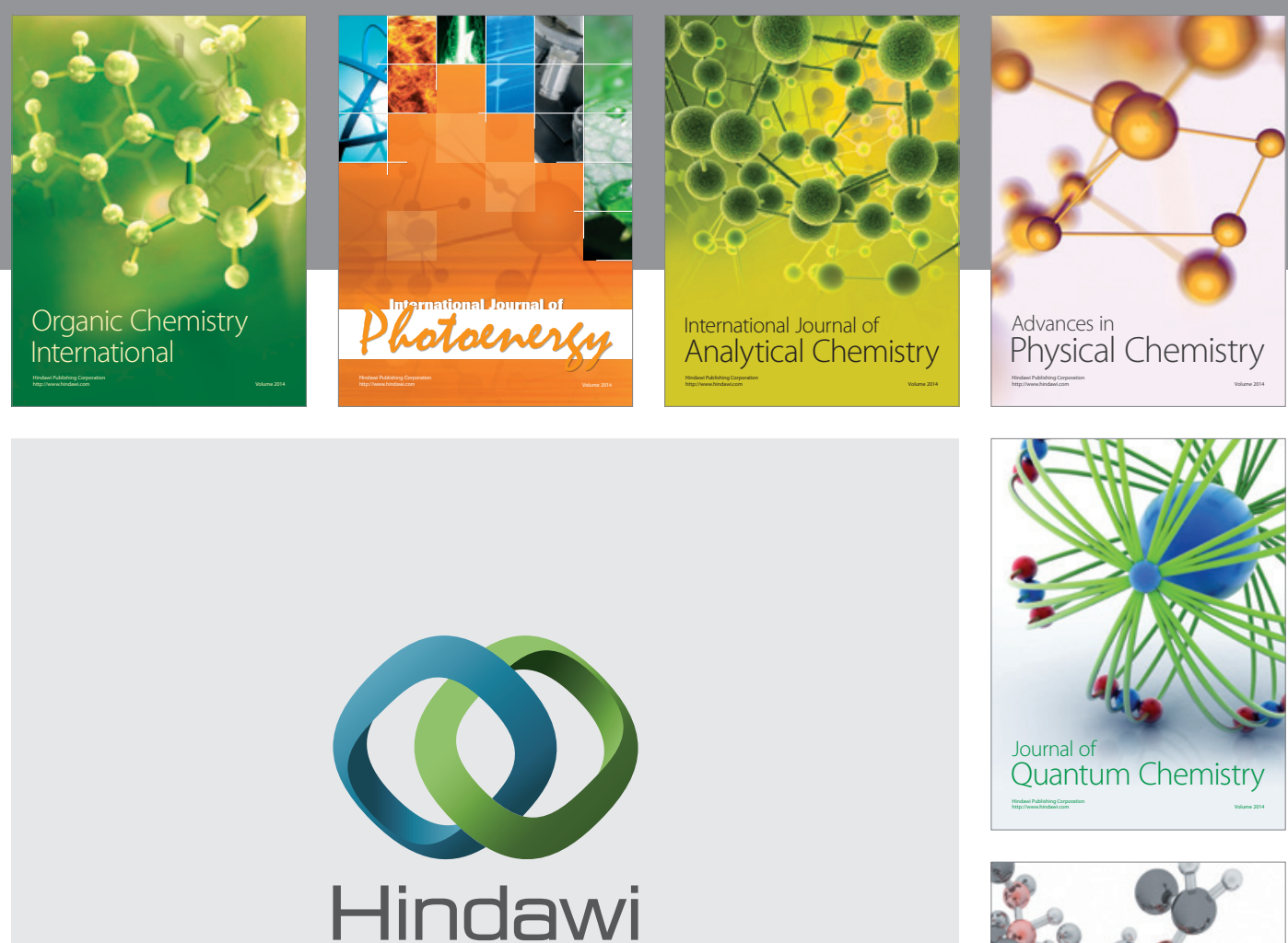

Submit your manuscripts at

http://www.hindawi.com

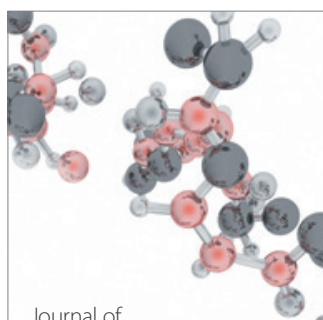

Analytical Methods

in Chemistry

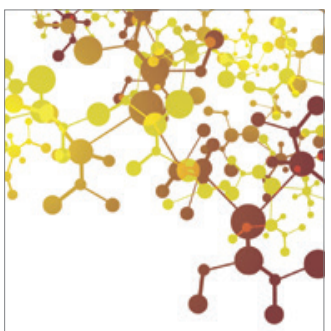

Journal of

Applied Chemistry

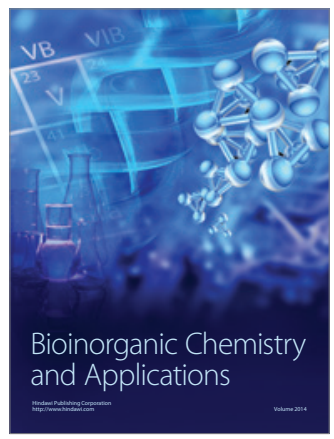

Inorganic Chemistry
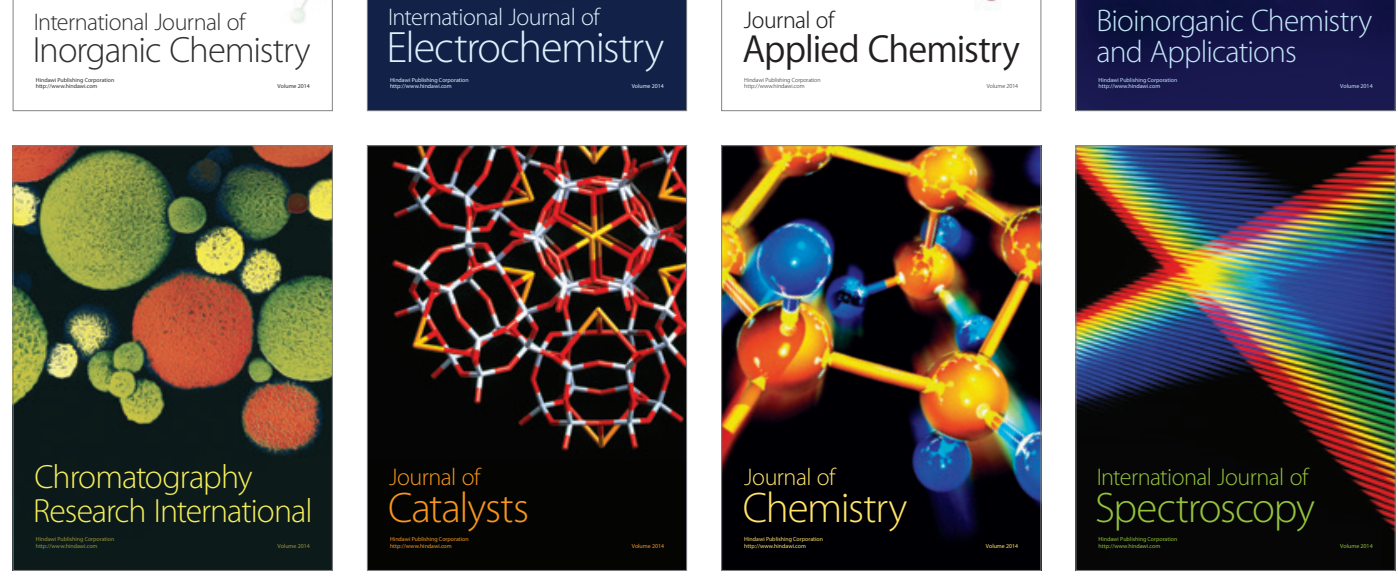